\title{
Editorial for the special issue on: transitions in society, energy, ecology, materials and other areas
}

\author{
Jean-Pierre Birat ${ }^{1, *}$, Gaël Fick ${ }^{2}$, Mauro Chiappini ${ }^{3}$, Dominique Millet ${ }^{4}$, Thècle Alix ${ }^{5}$, Andrea Declich ${ }^{6}$, Leiv \\ Kolbeinsen $^{7}$, and Valentina Colla ${ }^{8}$ \\ ${ }^{1}$ IF Steelman, Semécourt, France \\ ${ }^{2}$ IRT-M2P, Metz, France \\ 3 ArcelorMittal Research, Maizières-lès-Metz, France \\ ${ }^{4}$ Réseau ECO-SD, Paris, France \\ ${ }^{5}$ ENSAM-Bordeaux, Bordeaux, France \\ ${ }^{6}$ Knowledge \& Innovation, Rome, Italy \\ 7 NTNU, Trondheim, Norway \\ ${ }^{8}$ SSSA, Pisa, Italy
}

2020 was a very special year, indeed! The COVID-19 pandemic reminded us that viruses, including pathogenic ones, are part of the biodiversity of the ecosystems in which we are immerged and that a very strong interaction can take place, at the scale of the Plague or the Influenza pandemics of the historical past. This caused time to hiccup and to slow down its pace for months. The scientific life to which we were used suddenly froze. Thus, the $14^{\text {th }}$ Society and Materials Conference, SAM-14, planned for 11-12 May, 2020 in Bordeaux at the university and ENSAM, had to be cancelled.

Everything was ready to go when that decision was made. A program had been arranged from the answers to the Call for Papers received in January. Keynotes speakers had accepted to come to Bordeaux to share their worldviews. The Jean-Sébastien Thomas Award had been attributed to a "best paper" among a set of candidates.

The decision was then made to organize a new event in May 2021, which would be virtual and was to be called SAM-15. Papers selected for SAM-14 would be automatically accepted for SAM-15, if authors were willing to present an updated version in 2021. However, some authors had already sent written contributions to the conference organizing committee and it was decided to collect and present them in a special issue of Matériaux et Techniques, if they willing to go along with this format and passed a further peer-reviewing test.

The present special issue is the result of this exercise, where 9 peer-reviewed papers based on contributions to SAM-14 are brought together, out of 38 presentations and keynotes, and 16 posters. The issue is organized around the theme of transitions, a lively, contemporary concept at the

\footnotetext{
* e-mail: jean-pierre.birat@ifsteelman.eu
}

nexus between environmental and societal issues that stresses roadmaps, action plans and policies, and therefore fits right at the core of SAM topics.

To introduce the content of this special issue, a philosophical digression, proposed by Pierre Caye, is in order [1,2]. Indeed, in [1], he points out that beyond the concepts of sustainable development and of the preservation of the Earth for future generations, there are not many policies or actions that seem capable of achieving these grandiose objectives beyond plain story-telling. Then he goes on to work, as a philosopher, and to propose a series of new concepts that would make it possible to sustain the challenge.

First, he notices that sustainability has a strong timecomponent, but that time in this expression ought to be considered not simply as an external parameter, which mankind and nature have to endure, but as a plastic variable that society has to shape and mold in order to deliver the future of mankind (and of the Earth), which will only exist if we make the effort of ensuring the continuity of time and transmitting it to future generations: this is a vision of time that has never been quite considered until now in discussions of sustainability!

Second, he proposes that: (1) nature and society's creations (capital) be considered as world heritage, to become part of the enduring patrimony of the present and the future; (2) work should be understood as a maintenance activity rather than a permanent recreation resting on the concept of destructive creation, the relevance of which, today, is actually debatable, 100 years after its conceptualization by Joseph Schumpeter; (3) technology should be seen as an umbrella under which mankind should be protected, rather than put under threat or domination. 
One could also mention Nassim Nicholas Taleb, who warns us to dismiss the advice of sententious experts, to avoid being over-focused on foresight and to rely on uncertainty and to benefit from it [3].

The article by Birat [4] tackles the concept of transition, i.e. one of the words commonly used today to transform the abstract concepts of sustainability into practical roadmaps and action plans. The energy transition is particularly ubiquitous in the narratives of governments, international institutions, NGOs and even businesses. Birat tracks the origin of the expression, from the Energiewende of Germany to its fuzzier impersonation in other countries. The expression then shifted to ecological transition, which points to the target of reducing GHG emissions drastically. Transition is also used elsewhere now, in a quasi-universal way: see for example the numerical transition (digitalization) of the $4^{\text {th }}$ Industrial revolution, but also many, many other transitions. As if transitions were amenable to planning and management, whereas revolutions are not - a case of relying on organization, foresight and order rather than on serendipity and black swans (or white rhinos) to move the future, running counter to Taleb's advice. Anyway, pick the winner according to your own taste.

The next articles concentrate on methodology with nice examples of their implementation.

The second article by Birat [5] deals with a more classical and enduring topic within SAM literature: how do LCA and MFA compare, particularly from the standpoint of their "usefulness" to business? Are they competing methods, among which one should choose one's own favorite, or rather complementary tools, casting light on different aspects of the same reality? The author stresses the point that LCA is already part of the toolbox of businesses, either materials, manufacturing industries, services and PSS (Product Service Systems), while MFA is still not used widely enough in strategic planning at corporate level.

Declich et al.'s article [6] proposes an investigation into how small business deals with the concepts of energy efficiency and of circular economy, both transition narratives pointing to transitions towards decarbonization and dematerialization. They were developed mainly by institutions and readily adopted by big business. What do SMEs bring, which is special and original in this area? The authors explain how SMEs are the practical actors implementing the transitions in an operational way, by embedding them in their daily business culture and staying close to a deeper understanding of what is a material in terms of energy savings and circularity: this is what is meant by stating that materials are social constructs!

Gobert et Allais [7] explored the conditions for implementing a repair and reuse network of consumer goods in a series of research \& action projects, which saddles between engineering and social sciences. They conducted a practical, experimental study of practices adopted in a particular French territory in the North of the French Alps, by interviewing players in the field, analyzing how they liaise with their "suppliers", describing their network and their interacting cultures. Their approach is a kind of anthropological or even ethnographic study, using quantitative methods from engineering sciences or geography.

The article by Peters [8] deals with the implementation of the thermodynamic concept of chemical exergy as an LCA indicator for resource scarcity (concentration exergy scarcity). The methodology is under development, which is fine as far as SAM papers are concerned, because the conference is a forum where new methods are presented while still under implementation, as in a thoughtexperimental laboratory where innovative ideas are explored. The paper belongs to an area of current development, where thermodynamic concepts are examined to serve as indicators in LCA or other methodologies, bringing along the tight arguments and the depth that one of the most essential physical theory can offer for the evaluation of a sustainability footprint [9]. In a similar vein, note also that the word entropy in old Greek means "transition" [4].

Kolbensein [10] uses thermodynamics further in actually examining process engineering as a means to describe the sustainability footprint of aluminum, as a major metal. He discusses important issues related to that metal, from its impact on mining to its recycling, thus from cradle to circular reuse. The social value of aluminum is described positively by producers. However, there remains a few caveats: the production of waste ( red mud) in the synthesis of alumina from bauxite ores by the "old" Bayer process is still not widely embarked in the circular economy, although resurrecting old technologies like the Perdersen process might change the deal; recycling is also lagging behind compared to other metals (iron, copper, lead, etc.) and other materials (paper).

The last 3 articles, all stemming from SSSA in Pisa, deal with applications of the pluridisciplinary approach advocated by SAM conferences. They are tightly connected with environmental issues, as apprehended by industry in a more classical way, particularly the steel industry.

The first article deals with water management in the steel sector, an important area related to sustainability, where the paper claims that progress can easily be achieved by implementing new water treatment technologies and careful management of the resource through the implementation of an exhaustive set of KPIs [11].

The last two articles $[12,13]$ tackle the interface between steel production and digitalization. They present digitalization as an enabler of the circular economy and of industrial symbiosis. The expression of ENVIRONMENT 4.0 is proposed as a quid pro quo to INDUSTRIE 4.0. As a matter of fact, digitalization is here to stay and prosper and it should help improve productivity, in the 3 dimensions of sustainable development. How much social value and how many jobs it will create is, however, an open matter.

The papers are very much in line with the general program of SAM conferences.

For the reader's information, the program of SAM-14 is given in the Appendix A. 


\section{Appendix A: Program of SAM-14 conference}

Session 1: New Ways to look at the circular economy Keynote Lecture: Sylvain SOURISSEAU, ADEME, France

Recycling of plastics and LCA: demonstrating the key technical aspects of the recycling chain, providing methodological guidance, PALLUAU, Bleu Safran, France

Has Copper content in steel been increasing due to recycling? I. DAIGO, University of Tokyo, Japan

Challenges and options for the recycling of present and future batteries, M. WEIL, KIT, Germany

Quantifying Current And Future Recycling Potential Of Lithium And Cobalt: Focus On Batteries, R. HORTA ARDUIN, University of Bordeaux, France

Selective recycling strategy for electrical engines from EV, G. GRIMAUD, MTB Recycling, France

Session 2: A richer view of mobility

Determining parameters influencing the environmental impacts of a car-sharing service using constraint modeling, O. GUYON, PSA, France

Preliminary life cycle assessment of a self-de-icing road system utilising intelligent bulk materials, A. PAVLOVIC, BSRIA, United Kingdom

Carbon pricing and the sustainability transition - the case of a car manufacturer's materials management, $\mathrm{N}$. IKEN, Renault, France

Personalized life cycle assessment - quantification of the carbon footprint of passenger cars taking individual aspects into account, A.-K. BRIEM, University of Stuttgart, Germany

LCA in the Space sector: what has been done so far? A. GALLICE, Ariane Group, France

Session 3: Digitalization as an enabler of sustainability

Keynote Lecture: Sustainable Development Goals: Strengths and weaknesses, Henri FRAISSE, ReSenTer, France

Influence of design properties of printed electronics on their environmental profile, T. PRENZEL, Fraunhofer Institute for Building Physics, Germany

A systematic literature review on environmental impact assessment approaches for digital services, VILLANUEVA, CentraleSupélec, France

ENVIRONMENT 4.0: digitalization and machine learning for improving the environmental footprint of the steel production processes, V. COLLA, Scuola Superiore Sant'Anna, Italy

Carbon and material impacts of urban transport policy - an econometric open data approach, J. PETERS, Universidad de Alcalá, Spain

Session 4: Social dimension of change and innovation

Keynote Lecture: Climate Change: To teach and to learn is to do one's own part, Arnaud DELEBARRE, Mines ParisTech, France

How to tell the story of change and transitions of the energy, ecological and societal systems, J.P. BIRAT, IF Steelman, France
SME's, energy efficiency, innovation: a reflection on materials and energy transition, A. DECLICH, Knowledge \& Innovation, Italy

Environmental, social and economic assessment of nature-based solutions: current state of the art and future perspectives, BABI IMENAR, LIST, Luxemburg

The beginning and the end of the aluminium value chain, L. KOLBEINSEN, NTNU, Norway

Development of operational sustainability performance targets for industrial research \& development, A.-L. HETTINGER, ArcelorMittal, France

Soil pollution on post-industrial sites: economic and environmental legacy, E. BAILLET, DREAL Grand Est, France

Session 5: Large scale features of materials flows and stocks

Keynote Lecture: Cédric PHILIBERT, IAE, France, Hydrogen, ammonia and more foresight visions.

A general theory of stock dynamics of populations and built and natural environments, R. BILLY, NTNU, Norway

Engineering New Materials From Biomass. A Multidisciplinary Object In Material Science And Beyond: Compost, J.-J. GAUMET, Institut Jean Barriol, France

How methodological limitations influence which raw materials are critical, D. SCHRIJVERS, University of Bordeaux, France

Variability in material composition of the energy system technologies: the surfer database, F. LAURENT, BRGM, France

Pathways towards a carbon neutral Swiss residential building stock, M. ROCA-PUIGROS, EMPA, Switzerland

Session 6: New ways to deal with energy and materials dissipation

Energy system pathways with low environmental impacts and limited costs - an analysis linking life cycle assessment and energy system modeling, L. VANDEPAER, PSI, Switzerland

Accounting for the dissipation of non-energetic abiotic resources in life cycle assessment: introducing interim characterization factors, CHARPENTIER-PONCELET, University of Bordeaux, France

An analysis on applicability of exergy-based methodologies in environmental sustainability assessment, LIU, University of Tokyo, Japan

Applying the GeoPolRisk method at midpoint and endpoint level as a complement to LCA: the case of Li-ion batteries for the EU., SANTILLAN-SALDIVAR, University of Bordeaux, France

Evaluating resource use of solar photovoltaic PANELSOACH, KOSAI, Ritsumeikan University, Japan

\section{Posters}

- Relevance Of Monetarization Methods For Eco-Design, A.-L. CAPOMACCIO, PSA, France.

- An empirical LCI methodology that encapsulates the recyclability of materials, P. DUNUWILA, University of Tokyo, Japan.

- Evaluation technico-économique et environnementale de l'utilisation des flux de matières, O. GIBOULOT, Centrale Nantes, France. 
- Practical feedbacks and reflections on the (im-)material flow analysis framework implementation, J. GOBERT, ENPC, France.

- Eco-design of additive manufacturing processes. Digital twin and LCA coupling, R. JULIO, Altran, France.

- ACEMIS: a tool to reduce the environmental footprint of airlines, R. JULIO, Altran, France.

- Social sustainability assessment of technologies for the energy transition - focus on societal acceptance, M. WEIL, KIT, Germany.

- Integrating criticality in Life Cycle Analysis of Nb, A. MAS FONS, University of Liège, Belgium.

- New sustainable business models based on Product Service Systems for the energy sector, the case of ENGIE, J. AYRAULT, Engie, France.

- Experimental and numerical study of innovative walls for resilient buildings: adaptation to climate change, $\mathrm{R}$. BOUZOUIDJA, University of Bordeaux, France.

- Paving the way for the optimization of water consumption in the steelmaking processes: barrier analysis and KPIs definition, T. BRANCA, Scuola Superiore Sant'Anna, Italy.

- Current and future aspects of the digital transformation in the European Steel Industry, T. BRANCA, Scuola Superiore Sant'Anna, Italy.

- DEEFI - Sustainability assessment in the concept of industry 4.0, B. DOUALLE, Altran, France.

- Socio-digital transformation in aircraft manufacturing, M. KOHLGRUBER, Technical University of Dortmund, Germany.

- RE-CYCLING. a circular approach for a circular economy, J. MARTINEZ LEAL, University of Bordeaux, France.

- Entropy, exergy and the nexus between thermodynamics and resource depletion, J. Peters, Universidad de Alcalá, Spain.

\section{References}

1. P. Caye, Durer, Éléments pour la transformation du système productif, Les Belles Lettres, 2020, 372 p.
2. R.-P. Droit, «Durer» de Pierre Caye: la chronique «philosophie - Le philosophe propose une profonde réorientation de nos manières de penser, pour sortir l'humanité de l'impasse» de Roger-Pol Droit, Le Monde (30 octobre 2020)

3. N.N. Taleb, Le cygne noir, La puissance de l'imprévisible, Les Belles Lettres, 2020, 608 p.

4. J.-P. Birat, Transitions, Matériaux et Techniques 108(5-6), $502(2020)$

5. J.-P. Birat, MFA vs. LCA, particularly as environment management methods in industry: an opinion, Matériaux et Techniques 108(5-6), 503 (2020)

6. A. Declich, G. Quinti, P. Signore, SMEs, energy efficiency, innovation: a reflection on materials and energy transition emerging from a research on SMEs and the practice of Energy Audit, Matériaux et Techniques 108(5-6), 505 (2020)

7. J. Gobert, R. Allais, (Im-)material flow analysis framework implementation on repair and reuse initiatives, Matériaux et Techniques 108(5-6), 509 (2020)

8. J.F. Peters, Reinventing exergy as indicator for resource depletion impacts in LCA, Matériaux et Techniques 108(5-6), 504 (2020)

9. H. Tveit, L. Kolbeinsen, The (love \& hate) role of entropy in process metallurgy, 506, Matériaux \& Techniques 107(5) (2019), https://doi.org/10.1051/mattech/2019028

10. L. Kolbeinsen, The beginning and the end of the aluminium value chain, Matériaux et Techniques 108(5-6), 506 (2020)

11. T. Annunziata Branca, I. Matino, V. Colla, et al., Paving the way for the optimization of water consumption in the steelmaking processes: barriers analysis and KPIs definition, Matériaux et Techniques 108(5-6), 510 (2020)

12. T. Annunziata Branca, B. Fornai, V. Colla, M. Maddalena Murri, E. Streppa, A. Johannes Schröder, Current and future aspects of the digital transformation in the European Steel Industry, Matériaux et Techniques 108(5-6), 508 (2020)

13. V. Colla, C. Pietrosanti, E. Malfa, K. Peters, Environement 4.0: How digitalization and machine learning can improve the environmental footprint of the steel production processes, Matériaux et Techniques 108(5-6), 507 (2020) 